\title{
A review of records and recovery actions for the 'Critically Endangered' Fiji Petrel Pseudobulweria macgillivrayi
}

\author{
DAVID PRIDDEL, NICHOLAS CARLILE, KOLINIO MOCE \\ and DICK WATLING
}

\section{Summary}

The 'Critically Endangered' Fiji Petrel Pseudobulweria macgillivrayi is believed to breed only on the island of Gau, Fiji, but its nesting grounds have yet to be located. Until a bird was captured in 1984, the species was known from only a single museum specimen (collected in 1855), one sighting on land (in 1965) and four unverified sightings at sea (1964-65). Local knowledge of the Fiji Petrel is restricted to a few lines of a traditional lullaby. In this paper we collate and review all records of the species, and examine all known attempts to locate nesting sites. Since 1985 there have been 15 reports of sightings on land and six at sea. Two additional specimens, both pre-breeding adults, have been obtained. Although our knowledge of this elusive species is slowly increasing, the timing of the breeding cycle remains uncertain, making the search for nesting sites particularly challenging. Known potential threats on Gau include predation by introduced cats, rats and pigs. We detail recent conservation efforts and prescribe some new initiatives, including the use of sniffer dogs. Locating the nesting grounds of the Fiji Petrel remains the prime conservation priority for this species.

\section{Introduction}

The Fiji Petrel Pseudobulweria macgillivrayi is a small, all-dark, gadfly petrel with a heavy bill. Formerly known from only a single museum specimen collected in 1855 (Gray 1859), a few unverified sightings, and the capture of a single bird in 1984 (Watling and Lewanavanua 1985), the Fiji Petrel is one of the world's most elusive and least-studied birds. It is thought to breed on the island of Gau in the Fijian archipelago but, despite several searches, nesting sites have yet to be discovered.

The Fiji Petrel is known locally as the kathau, but the indigenous people have no knowledge of its whereabouts or habits. Nothing is known about the species' population size, breeding ecology or foraging behaviour. Even the timing of its breeding cycle is uncertain. We presume that, like other Pacific members of the genus (Brooke 2004), the Fiji Petrel is strictly nocturnal at colonies, but confirmatory evidence is lacking. Despite the elusiveness of the Fiji Petrel, the people of Fiji have great pride in this enigmatic seabird; it is the emblem of a national airline (Air Fiji) and it features on the Fijian fifty-dollar banknote.

The Fiji Petrel is classified as 'Critically Endangered' because it is estimated, given the paucity of sightings, that there is only a tiny population which is confined to a very small breeding area (BirdLife International 2007b). Furthermore, it is assumed to be declining because of predation by introduced cats Felis catus and rats Rattus spp. (Watling and Lewanavanua 1985) and, more recently, pigs Sus scrofa. 
In this paper we: (i) collate, update and review all records of the Fiji Petrel; (ii) examine the extent and findings of all known surveys; (iii) report the collection of two additional specimens; (iv) investigate, as far as is possible, the timing of the breeding cycle; (v) describe recent conservation initiatives; and (vi) prescribe additional actions needed to conserve the species.

Avian nomenclature and taxonomy follow the BirdLife taxonomic checklist (BirdLife International 2007a). Place names and elevations are taken from the 1:50,000 topographic map of Gau Island published by the Fiji Department of Lands and Survey in 1996.

\section{The Island of Gau}

Gau Island $\left(18^{\circ} \mathrm{O} 2^{\prime} \mathrm{S}, 179^{\circ} 18^{\prime} \mathrm{E}\right)$ is situated $\sim 5 \mathrm{O} \mathrm{km}$ east of the main Fijian island of Viti Levu. It is $136 \mathrm{~km}^{2}$ in area, the fifth largest of Fiji's 332 islands. The island is of volcanic origin and rugged. Approximately $55 \%$ of the island, mostly the upland areas of the interior, support intact, dense tropical rainforest (Watling and Lewanavanua 1985). In contrast, the lowlands have been cleared extensively for settlement, agriculture and forest plantations. The high land in the north of the island is dominated by the peaks of Delaco $(715 \mathrm{~m})$ and Vatuvula $(705 \mathrm{~m})$ (Figure 1). From Delaco the main range runs roughly southeast to Koroninokonoko $(615 \mathrm{~m})$. Waiboteigau Creek, the island's major watercourse, flows from the southern flanks of this range toward the southeast. Historically (pre-1850), the hinterland was heavily used during periods of tribal warfare, and derelict earthworks and fortified refuges occur along many mountain ridges. In recent times, the islanders have adopted a more coastal existence, and walking tracks that once crossed the island no longer exist (Watling and Lewanavanua 1985).

The island's population of 3,115 people is largely dispersed among 16 coastal villages and one small settlement (Fiji Government Bureau of Statistics 1996 census). The majority exist on subsistence fishing and farming, with gardens tended up to $300 \mathrm{~m}$ above sea level. Small pine plantations have been established on the island, but there is no intensive agriculture or industry. Small-scale harvesting of coconuts for the production of copra provides a small source of income for some islanders.

A single unsealed road joins the villages, but there are very few vehicles. A shipping dock and a boarding secondary school are situated on the west coast near Nawaikama, and a grass airstrip at the southern end of the island provides a regular commercial air link to Suva, the nation's capital. The only regularly used inland trail leads south from Navukailagi to a telecommunication tower on a peak just below Delaco. This tower and the derelict earthworks mentioned above are the only man-made structures above $300 \mathrm{~m}$.

\section{Records of the Fiji Petrel}

In total, we collated 18 reports of the Fiji Petrel on land, all on the island of Gau (Table 1 ). Details of each report are contained in Appendix 1 in Supplementary materials. Two specimens were obtained: one in 1985, the other in 2007. Measurements and description of the 2007 specimen are contained in Appendix 2 in Supplementary materials.

We investigated, as far as possible, the veracity of each report. Reports were classified as either: (i) confirmed if the bird was retained as a specimen, or handled by one of the authors, or photographed and subsequently identified by the authors; (ii) of high reliability if the bird was not seen by the authors but the description given was correct; and (iii) of low reliability if the description was poor, incomplete or flawed. We do not regard as credible reports the six records designated as low reliability (see Table 1 ). They are included here for completeness, but have been omitted from all subsequent tallies and discussion. We found no records of the Fiji Petrel ashore elsewhere in Fiji, despite the suggestion (in BirdLife International 2007b) that they might also nest on Taveuni Island.

Of the 12 credible reports of Fiji Petrels on Gau (Table 1 ), 10 were of single individuals that landed in one of four villages: Nukuloa $(n=5)$, Nawaikama $(n=3)$, Levuka $(n=1)$ and 


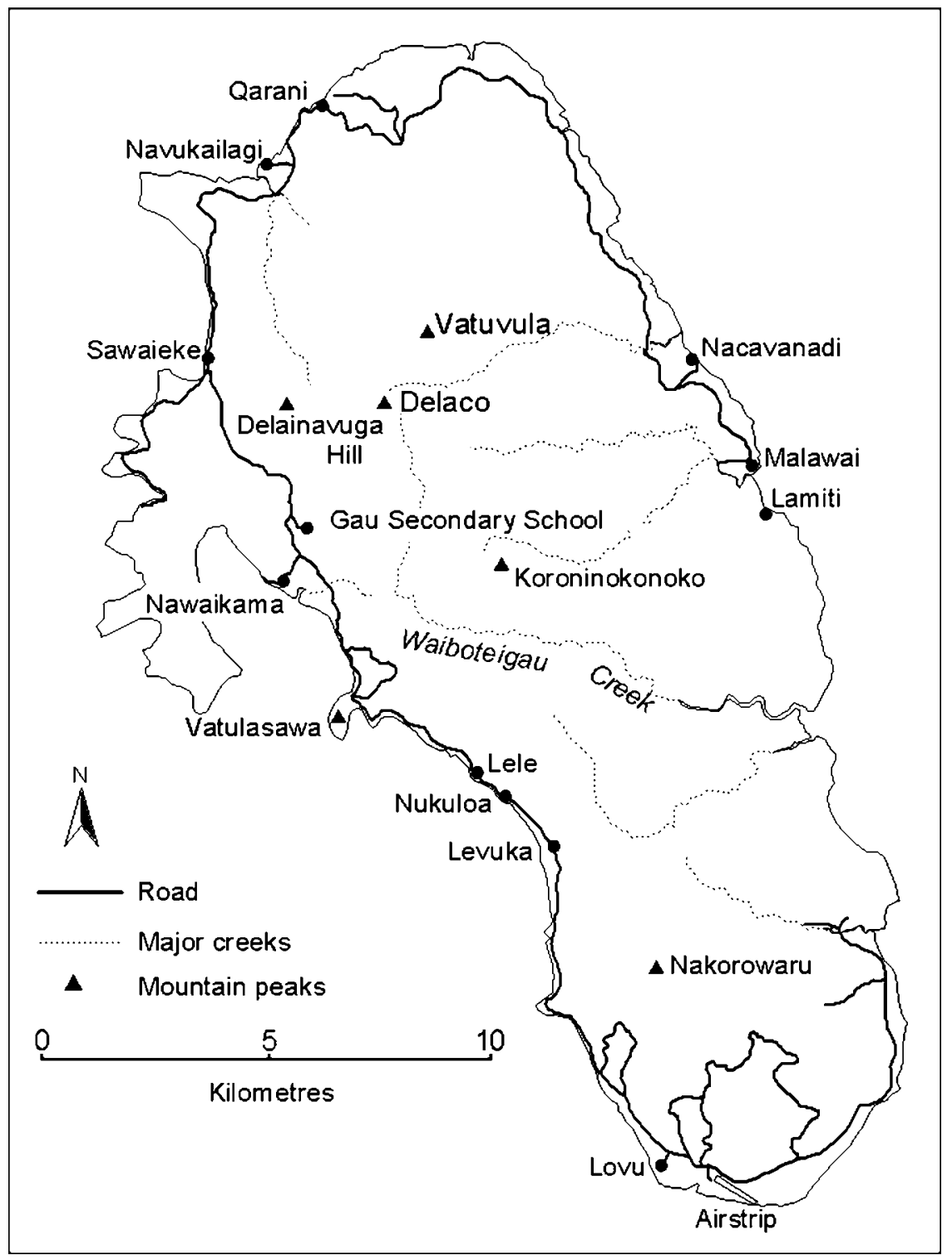

Figure 1. Map of the island of Gau showing places mentioned in the text.

Sawaieke $(n=1)$, all on the western side of the island (see Figure 1 ). The other two reports were the collection of the original specimen (from a site unknown) and the intentional luring (by spotlight) and capture of a bird near Delaco in the interior of the island.

Three additional sightings of Fiji Petrel were reported (see Appendix 1 in Supplementary materials), but upon further investigation were found to be erroneous, the species being misidentified. It appears that many islanders do not differentiate between Fiji Petrels and Collared Petrels Pterodroma brevipes, a species that also breeds on Gau (Watling 1986a). The population of Collared Petrels on Gau is unknown but it probably exceeds several hundred pairs. Also, the 
Table 1. Reported groundings of Fiji Petrels on Gau, Fiji. Additional details are contained in Appendix 1 in Supplementary materials. Reports were confirmed if the bird was either: (i) retained as a specimen, (ii) handled by the authors, or (iii) photographed and subsequently identified by the authors; of high reliability if the bird was not seen by the authors but the description given was correct; and of low reliability if the description was poor. Question mark indicates data not known.

\begin{tabular}{|c|c|c|c|c|c|}
\hline Year & Date & Location & Estimate reliability & Breeding status & Source \\
\hline 1855 & 02-17 October & Gau & Confirmed (specimen) & Immature & Gray 1859 \\
\hline 1965 & $?$ & Nukuloa & High & $?$ & K. Moce \\
\hline 1984 & 30 April & Near Delaco & Confirmed (handled) & Adult & $\begin{array}{l}\text { Watling and } \\
\text { Lewanavanua } 1985\end{array}$ \\
\hline 1985 & April or May & Nukuloa & High & $?$ & K. Moce \\
\hline 1985 & O3 July & Nukuloa & Confirmed (specimen) & Pre-breeding adult & K. Moce \\
\hline 1987 & 30 July & Nawaikama & High & $?$ & K. Moce \\
\hline 1987 & II October & Nawaikama & High & $?$ & K. Moce \\
\hline 1989 & 18 December & Nukuloa & Confirmed (handled) & $?$ & K. Moce \\
\hline 1990 & $?$ & Nawaikama & High & $?$ & K. Moce \\
\hline 2000 & December & Nukuloa & Low & $?$ & M. Ratu \\
\hline 2001 & $?$ & Nawaikama & Low & $?$ & M. Ratu \\
\hline$?$ & $?$ & Lele & Low & $?$ & Ratu 2004 \\
\hline 2002 & 29 December & Nukuloa & Confirmed (photographed) & $?$ & Ratu 2004 \\
\hline 2002 & December & Lamiti & Low & $?$ & Ratu 2004 \\
\hline 2003 & 26 June & Lovu & Low & $?$ & Ratu 2004 \\
\hline 2003 & 28 June & Nacavanadi & Low & $?$ & Ratu 2004 \\
\hline 2005 & 4 May & Sawaieke & Confirmed (photographed) & Adult & A. Taukei \\
\hline 2007 & 12 April & Levuka & Confirmed (specimen) & Pre-breeding adult & A. Taukei \\
\hline
\end{tabular}

remains of a Tahiti Petrel Pseudobulweria rostrata have been found on the island (Plant et al. 1989), suggesting that this species might also breed there. The potential for erroneous identification has important implications for the reliability of unverified records of groundings, particularly as it is this information upon which the timing of any future surveys and the areas to be searched are likely to be based.

\section{Records at sea}

Ten sightings of the Fiji Petrel at sea have been reported (Table 2). All have occurred since 1964, but none have been substantiated by specimens or photographs. Details of each report are contained in Appendix 3 in Supplementary materials. No attempt has been made to assess the veracity of these reports. It is possible that some are actually sightings of Bulwer's Petrel Bulweria bulwerii, a similar all-dark petrel that also occurs in the central Pacific.

\section{Surveys to locate the nesting grounds of the Fiji Petrel}

Several surveys have been undertaken to locate the nesting grounds of the Fiji Petrel on Gau (Table 3). To date, all have been unsuccessful. Details of each survey are contained in Appendix 4 in Supplementary materials.

\section{Conservation action}

Prior to confirmation of its continued survival in 1984 (Watling and Lewanavanua 1985), groundings of the Fiji Petrel went largely unreported. Any remains found by locals were apparently either buried or fed to dogs. Since 1984, more groundings have been reported, but the 
Table 2. Reported sightings of the Fiji Petrel at sea. Additional details are contained in Appendix 3 in Supplementary materials.

\begin{tabular}{|c|c|c|c|c|c|}
\hline Year & Date & Latitude & Longitude & Approximate location & Source \\
\hline 1964 & 8 November & $19^{\circ} 30^{\prime} \mathrm{S}$ & $176^{\circ} 30^{\prime} \mathrm{W}$ & $550 \mathrm{~km}$ ESE of Suva, Fiji & Bourne 1967 \\
\hline 1964 & 31 December & $24^{\circ} \mathrm{OO}^{\prime} \mathrm{S}$ & $178^{\circ} 30^{\prime} \mathrm{E}$ & $650 \mathrm{~km} \mathrm{~S}$ of Suva, Fiji & Bourne 1967 \\
\hline 1965 & I January & $21^{\circ} 30^{\prime} \mathrm{S}$ & $176^{\circ} 30^{\prime} \mathrm{W}$ & $140 \mathrm{~km}$ WSW of Nuku'alofa, Tonga & Bourne 1967 \\
\hline 1965 & 23 May & $10^{\circ} \mathrm{OO}^{\prime} \mathrm{S}$ & $180^{\circ} \mathrm{OO}^{\prime} \mathrm{E}$ & 360 km NE of Rotuma, Fiji & Bourne 1967 \\
\hline 1986 & 12 June & $18^{\circ} \mathrm{OO}^{\prime} \mathrm{S}$ & $179^{\circ} 13^{\prime} \mathrm{E}$ & Herald Bay, Gau Island, Fiji & D. Watling \\
\hline 1986 & August & $18^{\circ} 10^{\prime} \mathrm{S}$ & $178^{\circ} 50^{\prime} \mathrm{E}$ & Between Suva and Gau Island, Fiji & A. Tabaiwalu \\
\hline 1999 & Early October & $16^{\circ} 13^{\prime} \mathrm{S}$ & $179^{\circ} 10^{\prime} \mathrm{E}$ & $20 \mathrm{~km} \mathrm{~N}$ of Vanua Levu, Fiji & D. Watling \\
\hline 1999 & Early October & $15^{\circ} 55^{\prime} \mathrm{S}$ & $171^{\circ} 59^{\prime} \mathrm{W}$ & $230 \mathrm{~km}$ ENE of Tafahi, Tonga & D. Watling \\
\hline 2003 & 14 August & $05^{\circ} \mathrm{OO}^{\prime} \mathrm{S}$ & $150^{\circ} 20^{\prime} \mathrm{S}$ & $\begin{array}{l}\text { Kimbe Bay, West New Britain, } \\
\text { Papua New Guinea }\end{array}$ & H. Shirihai \\
\hline 2007 & 12 April & $\mathrm{OI}^{\circ} 42^{\prime} \mathrm{S}$ & $153^{\circ} 56^{\prime} \mathrm{E}$ & $\begin{array}{l}400 \mathrm{~km} \mathrm{~N} \text { of Bougainville, } \\
\text { Papua New Guinea }\end{array}$ & Howell 2007 \\
\hline
\end{tabular}

information obtained has been delayed, minimal and imprecise. Consequently, determining the veracity of some reports has been difficult. One of the underlying reasons for the lack of good information is the absence of ornithological expertise on the island. Data that could have been gleaned from grounded birds may have revealed critically important facets of the species' ecology, such as the timing of its breeding cycle.

To begin to understand the ecology of the Fiji Petrel, and ultimately to ensure the continued survival of the species, it is essential that information is extracted from those birds that do occasionally come to hand. Basic data that needs to be recorded includes: date, time, weather conditions, age, sex, weight, measurements, breeding condition, plumage condition and moult. A photographic record of each grounded bird would assist in confirming the species identification, and feather samples could be used for genetic studies. Accordingly, recent conservation action has focussed on educating the local community to ensure that: (i) all groundings are adequately reported; (ii) as many data as possible are collected from each grounded bird; and (iii) all dead specimens are retained.

In 1987, Dick Watling (with funding from the Australia and Pacific Science Foundation) initiated the first community awareness programme to be undertaken on Gau. This programme, run by Kolinio Moce and Filimone Kau through the National Trust of Fiji, produced and distributed posters and leaflets, and held meetings in all the villages and at the Secondary School.

Table 3. Surveys undertaken to search for the nesting grounds of the Fiji Petrel on Gau, Fiji. Additional details are contained in Appendix 4 in Supplementary materials.

\begin{tabular}{lll}
\hline Date & Participants & Source \\
\hline 17-21 February 1925 & Whitney South Sea Expedition, & Jenkins 1986 \\
& American Museum of Natural History & \\
October 1971 & J.B. Smart & King 1981 \\
July-August 1982 & Ornithologists from New Zealand & Lovegrove 1984 \\
May 1983-August 1984 & Dick Watling & Watling and \\
& & Lewanavanua 1985, \\
& Mike Imber, Andrew Brown, Dick Watling & Watling 1986b \\
17-26 June 1985 & Adrian Plant, Kolinio Qalo, & Plant et al. 1989 \\
15 September-9 & Kinijioji Vererusa and Dick Watling & \\
October 1987 & Dick Watling & \\
March 1989 & David Priddel, Nicholas Carlile and & Priddel and Carlile 2003 \\
June 2003 & Dick Watling & \\
\end{tabular}


In 2002, the National Trust of Fiji ran a follow-up awareness and education programme to further raise the profile of the Fiji Petrel and to educate the local community about the social and scientific significance of this species. The programme emphasised the importance of obtaining data from grounded birds and promoted the release of birds back into the wild, explaining how best to do this.

Both of these programmes have met with considerable success. Not only have the islanders developed an appreciation for the uniqueness of the Fiji Petrel, but they are now aware of the international concern for the bird's continued survival. Moreover, the local community on Gau appears strongly sympathetic to genuine attempts to protect and conserve this unique part of their natural heritage. Unfortunately, there has been a downside to the increased local and overseas interest in the Fiji Petrel. Rivalry has developed between villages, which now jockey and compete for 'ownership' of this iconic species and for the kudos and rewards that the species might bring to their community. Although the frequency of reported sightings has increased, some reports appear to be fictitious, making the task of collecting reliable data challenging. Increased interest has also had a negative consequence for the conservation of the species. Although the villagers have been encouraged to release any grounded birds found, interest within the community and from the media distracts the finder from doing so. Without the knowledge of how to feed petrels, any birds held in captivity are likely to die from starvation. The most recent bird to be found on Gau was kept for a week before it finally died.

After visiting Gau in 2003, the authors formulated an unofficial recovery plan for the Fiji Petrel (Priddel et al. 2003). This plan acknowledged that the only way of collecting reliable data from grounded birds (other than killing those birds that come to hand) was for locals to collect the information. Consequently, a key feature of the recovery plan was to develop local expertise to collect scientific data from any reported groundings. To facilitate this, Amania Taukei, a respected elder of Gau, visited several islands in New South Wales, Australia in December 2004 to receive training in the techniques of handling and identifying seabirds, collecting morphometric data, cloacal sexing and bird banding. He then returned to Gau where, in February 2005, he conducted a workshop to pass on some of his new-found knowledge to interested islanders. Taukei is now employed on an ongoing basis as a ranger by the National Trust and is charged with the responsibility of ensuring that groundings of any seabird are investigated and documented. Reports are forwarded to the National Trust and then to the authors of this paper. As a result of this initiative, recent groundings have provided much more information than was obtained previously.

Although any deaths of Fiji Petrel are to be avoided, dead specimens are of immense scientific value. They provide unequivocal data and material for scientific study, as well as the odour needed to train sniffer dogs. Taukei has also been charged with the responsibility of hastily retrieving any dead specimens and transporting them to Suva, where they can be dealt with appropriately.

Another action suggested in the recovery plan was an initiative aimed at gathering ecological information more quickly by increasing the frequency of groundings. This was to be done by using fixed spotlights to attract petrels to land at Gau Secondary School. The lights were to be switched on for the first few hours after sunset. The intent was for the students to go about their normal business, but to be vigilant for grounded birds at night. Under the guidance of a suitably trained local person, the students were then to gather information from any birds that grounded. Although most grounded birds were likely to be Collared Petrels, the experience gained in dealing with a relatively common species would prepare them well for processing the occasional Fiji Petrel. Unfortunately, we were unable to gain local permission to use the school for the purpose of attracting petrels. For a short period, islanders were employed to hand-hold lights on a nearby ridge. However, without birds continually falling from the sky, enthusiasm soon waned, and so this approach was abandoned.

\section{Discussion}

Currently, 35 species of petrels and shearwaters (Procellariidae) are threatened globally; nine are categorised as 'Critically Endangered', nine as 'Endangered', and 17 are listed as 'Vulnerable'. 
Table 4. Measurements of the Fiji Petrel. Additional details of the 2007 specimen are contained in Appendix 2 in Supplementary materials.

\begin{tabular}{lllllll}
\hline Specimen & Age & Sex & Weight $(\mathrm{g})$ & Wing $(\mathrm{mm})$ & Tail $(\mathrm{mm})$ & Tarsus $(\mathrm{mm})$ \\
\hline $1855^{\mathrm{A}}$ & Immature & Male & - & 205 & 85 & $35 \cdot 3$ \\
$1984^{\mathrm{B}}$ & Adult & - & 143 & 227 & 92 & 37 \\
2007 & Adult & Female & ${ }^{120^{C}}$ & 220 & 91 & $35 \cdot 3$ \\
\hline
\end{tabular}

${ }^{\mathrm{A}}$ Specimen measured by M. Imber and reported in Watling and Lewanavanua 1985

${ }^{\mathrm{B}}$ Data from Watling and Lewanavanua 1985

${ }^{\mathrm{C}}$ Bird had not eaten for a week

Another two species are extinct and 12 are 'Near-threatened' (BirdLife International 2008). Many of the rarer species have required considerable effort to locate their nesting grounds. Examples include the Bermuda Petrel Pterodroma cahow (Murphy and Mowbray 1951), Magenta Petrel P. magentae (Crockett 1994), Hawaiian Petrel P. sandwichensis (Simons and Hodges 1998) and Zino's Petrel P. madeira (Zino et al. 2001).

The Fiji Petrel is one of several Pacific petrels whose nesting grounds have yet to be discovered; others include Beck's Petrel Pseudobulweria becki and the New Zealand Storm-petrel Oceanites maorianus. Beck's Petrel is known from only two specimens collected in the waters of Papua New Guinea and the Solomon Islands by Rollo Beck in the late 1920s (Murphy 1930, Murphy and Pennoyer 1952) and a few recent unverified sightings in the same general area (Onley and Scofield 2007). The New Zealand Storm-petrel, previously known from only fossil material and three $19^{\text {th }}$ Century specimens, has been sighted many times since 2003 in the Hauraki Gulf of New Zealand (BirdLife International 2004, Gaskin and Baird 2005).

Until recently, the precise nesting locality of the Mascarene Petrel Pseudobulweria aterrima was also unknown, but now several likely sites have been identified, mostly in the Grand Bassin area on Reunion Island (Le Corre et al. 2003). These sites were identified only on the basis of nocturnal vocal displays of airborne birds; actual nests still remain to be discovered (M. Le Corre, pers. comm.). Similarities between the current state of knowledge for the Fiji Petrel and the past situation for the Mascarene Petrel gives cautious optimism that the nesting grounds of the Fiji Petrel on Gau Island will eventually be discovered.

\section{Location of the nesting grounds}

The Fiji Petrel must have bred on Gau in 1855 because the holotype that was collected there is an immature with incompletely grown flight feathers. Judging from the number of recent records of the Fiji Petrel on Gau (Table I) it is almost certain that the species still breeds there. Unfortunately, there is no definitive information as to the precise location of the breeding site or sites.

Due largely to the education and awareness programmes, the indigenous people of Gau are now not only aware of the rarity and significance of the Fiji Petrel, but they have acquired a much greater appreciation of the need to conserve their remaining forests. The community leaders have committed themselves to protecting, in perpetuity, any area of land found to contain nesting Fiji Petrels (Ratu 2004). Discussions and workshops with villagers to initiate full protection for the Gau highlands are ongoing.

The human population of Gau is confined almost entirely to the coastal lowlands, and few people venture into the rugged hinterland. The lack of local knowledge about the Fiji Petrel suggests that it probably nests in the interior. A traditional lullaby about the Fiji Petrel (Appendix 5 in Supplementary materials) demonstrates some rudimentary knowledge of the bird's behaviour and we suspect that previous generations were familiar with the species, possibly because they used the interior of the island much more extensively. 
Imber (1986) considered the central ridge running most of the length of Gau to be the most likely nesting site of the Fiji Petrel. He based this opinion on evidence that Pseudobulweria is closely related to Procellaria (Imber 1985), and that the latter prefer ridge tops for siting their burrows. He also presumed that the Fiji Petrel would head south to feed, attracted to deeper, colder, more productive waters. These beliefs, together with the locations of groundings on the western side of Gau, led him to believe that the nests were most likely to be located somewhere in the vicinity of Delaco or Koroninokonoko. Consequently it is here that most effort has been focussed.

Extensive searches of many ridgelines, chiefly around Delaco, however, have proved fruitless, suggesting it may now be time to consider other possibilities. When Rollo Beck visited Gau in 1925 he trekked from Sawaieke to "the summit" (presumably Delaco) and recorded that "the chief finally went with me to the top of the island where I understood that shearwaters [petrels] nest, but when we stood on the top, after a rough climb, he pointed down to dense canyons on the far [eastern] side of the island saying that the birds nested there" (Jenkins 1986). Consequently, future searches should include the eastern side of Gau, particularly the headwaters of Waiboteigau Creek. Other petrels breed in similar habitat elsewhere. For example, on Chatham Island, the Magenta Petrel nests within dense forest near a river tributary about $5 \mathrm{~km}$ inland (Aikman et al. 2001).

\section{Timing of the breeding cycle}

Logistical difficulties associated with undertaking upland searches on Gau make the task of locating the nesting grounds of the Fiji Petrel exceedingly challenging. The current dearth of information about the timing of the breeding cycle exacerbates the problem. Typically, petrels are absent from their nesting grounds for about half the year, and are most detectable during the brief periods of courtship and egg-laying, when they engage in noisy courtship flights and vigorously defend nest burrows. Breeding petrels returning to land to feed their chicks typically arrive and depart quickly and silently. Consequently, searches for the Fiji Petrel would be more likely to be successful if the timing of the breeding cycle were known.

Characteristics of localities near where birds have been found on Gau suggest that these individuals grounded after becoming disorientated by unshielded electric lights. Based on similar experiences elsewhere, the grounded birds are likely to be fledglings or inexperienced breeders. Of the 2,348 seabirds that grounded on Reunion Island between January 1996 and December 1999, > 90\% were recently fledged birds (Le Corre et al. 2002, Le Corre et al. 2003). As many procellariiforms have a fairly synchronous breeding season, groundings of fledglings are often restricted to a few months. Thus, for most species, the timing of groundings usually provides a good indication of the time of fledging, from which the timing of the breeding cycle can be estimated. For the Fiji Petrel, reported groundings span many months (April to December), and two of the three birds whose breeding status is known were not fledglings but pre-breeding adults. Other studies have shown that pre-breeding procellariiforms visit the nesting grounds from mating time to about midway through the chick-rearing period (e.g., Serventy 1967).

The time taken for adult petrels to incubate their eggs to hatching and to rear their chicks to fledging are both dependent on body size, with larger species taking longer for both processes (Warham 1990). Warham calculated the relationship between incubation length ( $y$, in days) and body mass ( $x$, in g) to be $y=26.33 x^{0.116}$ (Warham 1990: 319). He also calculated the relationship between nestling period $(y)$ and body mass $(x)$ to be $y=22.72 x^{0.229}$ (Warham 1990: 356). By (i) using these equations, (ii) assuming an adult body weight of $143 \mathrm{~g}$ (Watling and Lewanavanua 1985), and (iii) adding an arbitrary 10\% variation, we estimate the incubation period of the Fiji Petrel to be $42-52$ days and the nestling period to be $64-78$ days.

The period between the return of breeding birds and egg deposition varies considerably among species according to body size and migratory status. For gadfly petrels it is about $30-38 \%$ of the 
whole reproductive cycle (Warham 1990: 237). Based on the combined estimate for incubation and chick-rearing (106-130 days), we calculate the period between return to the colony and egg laying to be 45-79 days. Mating takes place during this period. As far as is known, all petrels (or at least the females) go to sea after mating, while the egg is being formed (Warham 1990). When the females return they lay almost immediately. The duration of this pre-laying exodus is highly variable among species (Warham 1990: 258-259). Typically, it is about 14-21 days, but for some species such the Hawaiian Petrel Pterodroma sandwichensis it is about 40 days (Baker and Coleman 1977, Simons 1985). Thus, we assume the duration of the pre-breeding exodus for the Fiji Petrel to be between 14 and 40 days.

There is only one record (the type specimen) where the bird was confirmed to be recently fledged. As best as can be ascertained, this individual was captured sometime during 2-17 October. Using the estimates above, we surmise that this bird probably hatched in the second half of July or first half of August, and the egg was probably laid sometime in late May, June or early July (Table 5). Mating would then have probably occurred sometime between mid April and mid June, the birds having first returned to the colony sometime between early March and mid May (Table 5). Typically, activity of petrels at the nesting grounds is most apparent in the three weeks or so prior to mating (e.g., Baker and Coleman 1977). For Fiji Petrels this is likely to be sometime during April or May. These estimates, based on a single estimated date of fledging, a single adult mass and some guesswork, should be interpreted cautiously. Moreover, the further we extrapolate backwards from the presumed fledging date, the lower the level of precision (Table 5).

There are confirmed records of Fiji Petrels present on Gau in April, May, July, October and December (Table 1). All other records, both reliable and otherwise, fall within this period-April to December. Groundings in October-December (presumably of young) suggest that breeding may not be highly synchronous, with both egg laying and fledging spanning several months (May-August and September-December respectively). There are no records of birds on land for the period January to March inclusive. We conclude (albeit with a great deal of uncertainty) that the Fiji Petrel probably breeds over a protracted period during the austral winter and spring, and those birds that ground on Gau are most likely either pre-breeders (approximately April to August) or juveniles on first departure from the colony (approximately September to December). Again, these conclusions are based on the interpretation of scant, fragmented data and should be used with caution. Data from additional groundings of fledglings, or from nests (when they are found), will help to better clarify the exact time of breeding. Congeners include both winter- and summer-breeding species (Le Corre et al. 2003, Villard et al. 2006, Shirihai 2008, P. Raust in litt.), providing little indication as to the likely breeding cycle of the Fiji Petrel.

\section{Threats}

Although the size of the Fiji Petrel population is not known, the infrequency with which this distinctive petrel is sighted and the elusiveness of its nesting sites suggest that there must be few birds. Consequently, the species is regarded as highly vulnerable to extinction. As little is known about the ecology of the Fiji Petrel we can only guess as to the nature and extent of any threats.

Fortunately, Gau is free of mongoose, a serious predator of ground-nesting birds on many of Fiji's larger islands. However, cats have been introduced to Gau and are present on the highest ridges (Watling and Lewanavanua 1985) where they are known to kill and consume Collared Petrels (Imber 1986). Pacific Rats Rattus exulans also occur on the ridges. Brown Rats $R$. norvegicus pose a far greater threat to small petrels (Towns et al. 2006), but have been trapped only at the villages (Imber 1986). The highly destructive Black Rat $R$. rattus is also reported to be present on Gau (Morgan Williams cited in Jenkins 1986), but its distribution is unknown. Cats and rats have caused many local extirpations of petrels (Moors and Atkinson 1984). As far as we can ascertain, there are no cliffs or inaccessible mountain ledges on the island of Gau where petrels could nest out of the reach of either cats or rats. Domestic pigs roam free around the 
Table 5. Estimated dates of mating, laying and hatching of Fiji Petrel based on: (i) a single fledging date of 2-17 October, (ii) a nestling period of $64-78$ days, (iii) an incubation period of $42-52$ days, (iv) an exodus period of $14-40$ days, and (v) a period between return to the colony and egg laying of 45-79 days.

\begin{tabular}{llllll}
\hline & Arrival & Mating & Egg laying & Hatching & Fledging \\
\hline Earliest & 7 March & 15 April & 25 May & 16 July & 02 October \\
Latest & 18 May & 19 June & 03 July & 14 August & 17 October \\
Range (days) & 72 & 65 & 39 & 29 & 15 \\
\hline
\end{tabular}

villages and plantations, and a feral population has recently established in the southern hinterland (Ratu 2004). This is a serious emerging threat as pigs have caused the demise of seabirds on numerous other islands around the world (see review by Moors and Atkinson 1984). If nests are not located and protected soon, the Fiji Petrel may be lost forever.

We presume that, like most other petrels, Fiji Petrels nest either in earth burrows or in natural cavities. If this species is a cavity-nester there is an abundance of natural holes, crevices and cavities on Gau in which it can nest. If it nests in earth burrows there is the potential for competition from Collared Petrels, which are of a similar size. Imber (1986) raised the possibility that the loss of Collared Petrel colonies on the main Fijian island of Viti Levu may be driving a compensatory increase on Gau. If so, competition for existing burrows, including those used by Fiji Petrels, may be intense. Fiji Petrels are not only at a competitive disadvantage numerically, but also temporally, as their breeding season probably begins later than that of the Collared Petrel (young Collared Petrels are in the nest from May to August; Watling 1986a).

\section{Future conservation action}

Although we have written a recovery plan for the Fiji Petrel to guide our own actions, the plan has not been officially adopted or sanctioned by the Fijian Government and has no legal standing. To date, the impetus to locate and conserve the Fiji Petrel has come primarily from Watling working collaboratively with the National Trust of Fiji and with scientists from Australia and New Zealand. This situation is unlikely to change in the foreseeable future.

The Fiji Petrel is extremely rare and any losses due to predation at the nesting grounds are of major concern. The control or eradication of cats, rats and pigs across the whole of Gau would help protect the species, but the size of the island and the presence of both a large human population and free-ranging livestock make this goal highly problematic. However, local predator control around the petrel's nesting grounds may be achievable. Such action requires knowledge as to the whereabouts of the nesting grounds; knowledge that is currently lacking. Thus, finding the nesting sites of the Fiji Petrel is paramount if the species is to be conserved. Now that a population of feral pigs has established on Gau, the need to locate the nesting grounds becomes even more urgent.

Until recently, the nesting grounds of the Magenta Petrel on Chatham Island were also unknown. After numerous searches, the nests were eventually located using radio telemetry (Imber et al. 1994). Birds were attracted to lights, captured and fitted with minature radiotransmitters, released and then radio-tracked to their nesting grounds. This technique requires specialised skills and equipment, and detailed knowledge of transmitter attachment procedures. It cannot be done opportunistically on Gau using local personnel, particularly when it involves such a critically endangered species. Radio-tracking would only be feasible if groundings proved to be a regular or predictable occurrence. With one notable exception, attempts to attract Fiji Petrels with spotlights have so far failed. Obtaining recordings of vocalisations may improve the chances of attracting birds, but there have been no reports of grounded birds vocalising.

The recent acquisition of a freshly dead specimen provides the best opportunity yet to locate the nesting grounds of the Fiji Petrel. Some feathers from this specimen have been removed and are to be used to train sniffer dogs (known in New Zealand as wildlife search dogs) to seek out nesting Fiji Petrels by scent; a technique that has proved successful in locating nests of the 
Magenta Petrel (Aikman et al. 2001). To make the dog team as mobile as possible they would need to be re-provisioned every few days. Searches will be planned on the basis that the Fiji Petrel breeds during the austral winter, with young present in the nest at least between June and October. Quarantine issues associated with the international transfer of dogs and a current absence of funding remain the only obvious obstacles.

Once the nesting grounds have been located, a research programme will need to be established to: (i) improve our understanding of the ecology and demography of the species; (ii) assess breeding success; and (iii) evaluate the causes of egg, chick and adult mortality. Solutions to any identified threats should then be developed, and action taken to ameliorate them. Predator control around the nesting grounds is the most likely conservation action that will need to be undertaken.

\section{Acknowledgements}

The awareness programmes on Gau and the expeditions in search of this species would not have been possible without the support of the local community. In particular, we gratefully acknowledge the support of Ratu Marika Lewanavanua, Paramount Chief of Gau, and Savenaca Waqa, Chief of the village of Navukailagi. We gratefully acknowledge the assistance of the National Trust of Fiji since the inception of the research undertaken by Dick Watling. Milika Ratu and Amania Taukei of the National Trust of Fiji assisted in all aspects of the work since 2002. We also acknowledge the generous support of the Wildlife Conservation Society, BirdLife International, the Department of Environment and Climate Change (New South Wales), the Tasmanian Conservation Trust and Environment Consultants Fiji. We thank the staff of the Fiji Museum for making available to us their only specimen of the Fiji Petrel. Walter Boles, Curator of Birds at the Australian Museum, travelled to Fiji to prepare the most recent specimen of Fiji Petrel. Adrian Plant kindly provided field notes from his visit to Gau. We thank Robert Wheeler, Mike Imber, Matthieu Le Corre, Guy Dutson and an anonymous referee for providing useful comments on an earlier draft of the manuscript.

\section{References}

Aikman, H., Davis, A., Miskelly, C. M., O'Connor, S. and Taylor, G. A. (2001) Chatham Islands threatened birds: recovery and management plans. Wellington, New Zealand: Department of Conservation.

Baker, A. J. and Coleman, J. D. (1977) The breeding cycle of the Westland Black Petrel (Procellaria westlandica). Notornis 24: 211-231.

BirdLife International (2004) New Zealand petrel causes a storm. Downloaded from http://www.birdlife.org/news/news/2004/02/ nz_storm-petrel.html on 30/08/2007.

BirdLife International (2007a) The BirdLife checklist of the birds of the world with conservation status and taxonomic sources. Version o. Downloaded from http://www. birdlife.org/datazone/species//downloads/
BirdLife_Checklist_Version_o.xls on 19/ OI/2008.

BirdLife International $(2007 \mathrm{~b})$ Species factsheet: Pseudobulweria macgillivrayi. Downloaded from http://www.birdlife.org on 19/01/2008.

BirdLife International (2008) Data zone. Downloaded from http://www.birdlife.org/ datazone on $19 / 01 / 2008$.

Bourne, W. R. P. (1967) Observations of seabirds and review of literature. Sea Swallow 19: 51-76.

Brooke, M. (2004) Albatrosses and petrels across the world. New York: Oxford University Press.

Crockett, D. E. (1994) Rediscovery of Chatham Island Taiko Pterodroma magenta. Notornis (Supplement) 41: 49-6o. 
Gaskin, C. and Baird, K. (2005) Observations of black and white storm petrels in the Hauraki Gulf, November 2003-June 2005: Were they of New Zealand storm petrels? Notornis 52: 181-194.

Gray, G. R. (1859) Catalogue of the birds of the tropical islands of the Pacific Ocean in the collection of the British Museum, London. London: Taylor and Francis.

Howell, S. (2007) Western Pacific Odyssey cruise: 2007 cruise narrative. Downloaded from http://wingsbirds.com/tours/narrative/ 170 on $25 / 07 / 2007$.

Imber, M. J. (1985) Origins, phylogeny and taxonomy of the gadfly petrels Pterodroma spp. Ibis 127: 197-229.

Imber, M. (1986) The plight of the Fiji Petrel Pseudobulweria macgillivrayi: a report of a visit to Gau Island in 1985. Australasian Seabird Newsletter 24: 8-12.

Imber, M. J., Crockett, D. E., Gordon, A. H., Best, H. A., Douglas, M. E. and Cotter, R. N. (1994) Finding the burrows of Chatham Island Taiko Pterodroma magentae by radio telemetry. Notornis (Supplement) 41: 69-96.

Jenkins, J. A. F. (1986) The seabirds of Fiji: an account based on the literature and recent observations. Australasian Seabird Newsletter 25: 1-70.

King, W. B. (1981) Endangered birds of the world: the ICBP bird Red Data Book. Washington, DC: Smithsonian Institution Press.

Le Corre, M., Ghestemme, T., Salamolard, M. and Couzi, F-X. (2003) Rescue of the Mascarene Petrel, a critically endangered seabird of Reunion Island, Indian Ocean. Condor 105: 387-391.

Le Corre, M., Ollivier, A., Ribes, S. and Jouventin, P. (2002) Light-induced mortality of petrels: a 4-year study from Reunion Island (Indian Ocean). Biol. Conserv. 105: 93-102.

Lovegrove, T. (1984) The south west Pacific expedition aboard the yacht Derwent 1982. Forest and Bird February: 21-28.

Moors, P. J. and Atkinson, I. A. E. (1984) Predation on seabirds by introduced animals, and factors affecting its severity. Pp. $667-690$ in J. P. Croxall, P. G. H. Evans and R. W. Schreiber, eds. Status and conservation of the world's seabirds. Cam- bridge: International Council for Bird Preservation.

Murphy, R. C. (1930) Birds collected during the Whitney South Sea Expedition. Am. Mus. Novit. 419: 1-15.

Murphy, R. C. and Mowbray, L. S. (195I) New light on the Cahow, Pterodroma cahow. Auk 68: 266-280.

Murphy, R. C. and Pennoyer, J. M. (1952) Whitney South Sea Expedition of the American Museum of Natural History (1920-1941). Larger petrels of the genus Pterodroma. Am. Mus. Novit. 1580: 1-43.

Onley, D. and Scofield, P. (2007) Albatrosses, petrels and shearwaters of the world. London: Christopher Helm.

Plant, A. R., Qalo, K. M., Vererusa, K. and Watling, D. (1989) A Tahiti Petrel (Pseudobulweria rostrata) from Gau Island, Fiji. Notornis 36: 149-150.

Priddel, D. and Carlile, N. (2003) Report on an expedition to Gau Island, Fiji, to search for the Fiji Petrel Pseudobulweria macgillivrayi, June 2003. Unpublished report to the Wildlife Conservation Society. Hurstville, Australia: NSW National Parks and Wildlife Service.

Priddel, D., Carlile, N. and Watling, D. (2003) Recovery plan for the critically endangered Fiji Petrel Pseudobulweria macgillivrayi. Hurstville, Australia: NSW National Parks and Wildlife Service.

Ratu, M. (2004) Gau Island final report. Unpublished report. Suva: National Trust of Fiji Islands.

Serventy, D. L. (1967) Aspects of the population ecology of the short-tailed shearwater Puffinus tenuirostris. Pp. $165-190$ in D. W. Snow, ed. Proceedings of the XIV International Ornithological Congress, Oxford, 1966. Oxford: Blackwell Scientific Publications.

Shirihai, H. (2008) Beck's Petrel. Bull. Brit. Ornithol. Club 128: 3-16.

Simons, T. R. (1985) Biology and behaviour of the endangered Hawaiian dark-rumped petrel. Condor 87: 229-245.

Simons, T. R. and Hodges, C. N. (1998) Darkrumped Petrel (Pterodroma phaeopygia). Pp. 1-24 in A. Poole and F. Gill, eds. The birds of North America. Philadelphia: The Birds of North America Inc. 
Towns, R. T., Atkinson, I. A. E. and Daugherty, C. H. (2006) Have the harmful effects of introduced rats on islands been exaggerated? Biol. Invasions 8: 863-891.

Villard, P., Dano, S. and Bretagnolle, V. (2006) Morphometrics and the breeding biology of the Tahiti Petrel Pseudobulweria rostrata. Ibis 148: 285-291.

Warham, J. (1990) The petrels: Their ecology and breeding systems. London: Academic Press.

Watling, D. (1986a) Notes on the Collared Petrel Pterodroma (leucoptera) brevipes. Bull. Brit. Ornithol. Club 106: 63-70.
Watling, D. (1986b) Rediscovery of a petrel and new fauna records on Gau Island. Oryx 20: 31-34.

Watling, D. and Lewanavanua, R. F. (1985) A note to record the continuing survival of the Fiji (MacGillivray's) Petrel Pseudobulweria macgillivrayi. Ibis 127: 230233.

Zino, F., Oliveira, P., King, S., Buckle, A., Biscoito, M., Neves, H. C. and Vasconcelos, A. (2001) Conservation of Zino's Petrel Pterodroma madeira in the archipelago of Madeira. Oryx 35: 128-136.

\section{DAVID PRIDDEL*, NICHOLAS CARLILE}

Department of Environment and Climate Change, PO Box 1967, Hurstville, NSW 2220, Australia.

\section{KOLINIO MOCE, DICK WATLING}

NatureFiji-MareqetiViti, Box 2041, Government Buildings, Suva, Fiji.

${ }^{*}$ Author for correspondence; e-mail: david.priddel@environment.nsw.gov.au

Received I November 2007; revision accepted 19 March 2008 